\title{
A Modified Hypothesis on the Role of Conjugated Trienes in Superficial Scald Development on Stored Apples
}

\author{
Zhanyuan Du and William J. Bramlage \\ Department of Plant and Soil Sciences, University of Massachusetts, Amherst, MA 01003
}

Additional index words. $\alpha$ - farnesene, diphenylamine, Malus domestica

\begin{abstract}
Three experiments were conducted using 'Cortland' and 'Delicious' apples (Malus domestica Borkh.). Fruit varying widely in superficial scald susceptibility, because of either endogenous or experimentally induced conditions, were stored for various intervals at $\mathrm{OC}$ and evaluated for scald development at 20C. Samples were extracted periodically in hexane, and ultraviolet absorption spectra of the extracts were used to evaluate $\alpha$ - farnesene and conjugated triene (CT) relationships to scald development. CT concentrations were calculated using each of the three CT absorption maxima (258 - $290 \mathrm{~nm}, 269$ - $290 \mathrm{~nm}$, and 281- $290 \mathrm{~nm}$ ) and expressed accordingly as CT258, CT269, and CT281. The poor association of CT281 concentrations with scald development led us to propose that metabolic products of CT281 species are more likely to be associated with scald development than the species themselves.
\end{abstract}

Superficial scald of apples is one of the most extensively studied postharvest disorders of fruit (Ingle and D'Souza, 1989; Meigh, 1970). Huelin and Murray (1966) and Murray et al. (1964) first identified $\alpha$ - farnesene as a scald-inducing factor in the natural coating of apples. Huelin and Coggiola (1968, 1970a) found that it was not $\alpha$ - farnesene but its peroxidation to conjugated trienes (CTs) that was related to scald development.

Since the report of Huelin and Coggiola (1968), most studies of the physiology of scald development have included absorbance measurements of hexane extracts of fruit surfaces. Anet (1969) separated two CT species from in vitro peroxidized $\alpha$-farnesene, both having absorption maxima at $\approx 251,260,269$, and $281 \mathrm{~nm}$. Huelin and Coggiola (1970a) and Meir and Bramlage (1988) observed similar absorption maxima at 258,269 , and $281 \mathrm{~nm}$ using hexane extracts of natural apple surfaces. These maxima have been assumed to represent CTs present in apple surfaces. Due to high background absorbance at $\approx 260 \mathrm{~nm}$, Anet (1972) proposed measuring spectra only at $281 \mathrm{~nm}$ to avoid masking CTs. Although some interference occurred at this wavelength, it could be corrected by subtracting absorbance at $290 \mathrm{~nm}$ from that at $281 \mathrm{~nm}$. Since then, these measurements $\left(\mathrm{OD}_{281-290 \mathrm{~nm}}\right)$ have been used routinely to calculate $\mathrm{CT}$ concentrations. Correlations between $\mathrm{OD}_{281-290 \mathrm{~nm}}$ and scald occurrences are the basis for the widely accepted hypothesis that $\alpha-$ farnesene is peroxidized to CTs, an action that leads to cellular disruption and scald symptom development. Exogenously applied antioxidants inhibit peroxidation and scald development (Anet and Coggiola, 1974; Huelin and Coggiola, 1970a, 1970b), and endogenous antioxidants are associated with scald resistance (Anet, 1974; Meir and Bramlage, 1988).

CT species never have been isolated and identified directly from hexane extracts of apple surfaces, and their association with scald is based entirely on correlative data. Some inconsistencies among correlation coefficients between $\mathrm{OD}_{281-290 \mathrm{~nm}}, \mathrm{OD}_{268-290 \mathrm{~nm}}$, and $\mathrm{OD}_{258-290 \mathrm{~nm}}$ scald occurrences have been noted (Meir and Bramlage, 1988). We therefore undertook to 1) examine the

Received for publication 24 Aug. 1992. Accepted for publication 11 Feb. 1993. Massachusetts Agricultural Experiment Station paper no. 3077. This research was supported in part by experiment station project no. 517 and by grant no. US-1525-88 from the U.S.-Israel Binational Agricultural Research and Development Fund. The cost of publishing this paper was defrayed in part by the payment of page charges. Under postal regulations, this paper therefore must be hereby marked advertisement solely to indicate this fact. characteristics of ultraviolet (UV) absorbance of hexane extracts of apple surfaces with different scald potentials and 2) investigate CT changes, as indicated by absorption spectra, during the development of scald symptoms. Results of this investigation led us to reconsider the significance of $\mathrm{OD}_{281-290 \mathrm{~nm}}$ measurements in relation to the roles of CTs in scald development of apples.

\section{Materials and methods}

Apples were grown at the Univ. of Massachusetts Horticultural Research Center, Belchertown, Mass. In 1990, three experiments were conducted using fruit from mature trees grown under standard horticultural conditions.

Diphenylamine (DPA) treatment (Expt. 1). 'Cortland' apples (internal ethylene, $3 \pm 2 \mathrm{ppm}$ ) were harvested on 26 Sept. 1990. 'Delicious' apples (internal ethylene, $52 \pm 4 \mathrm{ppm}$ ) were harvested on 10 Oct. 1990. There were six single-tree replications of samples for each cultivar. Within 3 days of harvest, each replicate sample was separated into two lots of 80 fruit each. One lot was dipped in a solution of DPA at $2 \mathrm{~g} \cdot$ liter $^{-1}$ plus $227 \mathrm{~g}$ of $50 \%$ methyl 1-(butyl carbamoyl)-2-benzimidazocarbamate (benlate) and 454 grams of 3a,4,7,7a-tetrahydro-2-[(trichloromethyl)thiol]-1 $\mathrm{H}$ - isoindole1,3(2 H)- dione (captan) per 400 liters (to control decay) and the other lot was dipped in a solution of fungicide without DPA. Fruit were dipped for $20 \mathrm{sec}$, drained, and stored at $0 \mathrm{C}$ in air. After 4,8 , 12 , and 16 weeks, 10 fruit from each sample were removed from storage and extracted in hexane. After 16 weeks of storage, the remaining fruit were kept at $20 \mathrm{C}$ for 7 days and evaluated for scald, which was recorded as percent incidence. However, almost no scald developed on 'Delicious', so the fruit were returned to $0 \mathrm{C}$ for an additional 8 weeks plus 1 week at $20 \mathrm{C}$ for a second evaluation of scald.

Harvest time (Expt. 2). 'Cortland' apples were harvested on 26 Sept. 1990 (same maturity as in Expt. 1) and on 10 Oct. 1990 (internal ethylene, $57 \pm 14 \mathrm{ppm}$ ) from three two-tree replications, using the same trees as in Expt. 1. Fruit (70 fruit per replication) were stored at $0 \mathrm{C}$ for 30 weeks; an additional 70 fruit per replication from the 10 Oct. harvest were stored for 45 weeks. After storage, scald was evaluated and 10 fruit per replication were extracted in hexane after $0,2,4,7$, and 10 days at 20C. Scald development was recorded as percentage incidence and intensity of development, using a system of $1=1 \%$ to $10 \%, 2=11 \%$ to $33 \%$, 
$3=34 \%$ to $66 \%$, and $4=67 \%$ to $100 \%$ of surface area affected.

Storage temperature (Expt. 3). 'Cortland' apples were harvested on 5 Oct. 1990, with 200 fruit collected from each of six replicate trees (internal ethylene, $31 \pm 13 \mathrm{ppm}$ ). Each replication was divided into four sublots of 50 fruit each. Two sublots were stored at $0 \mathrm{C}$ for 12 or 24 weeks and two were kept at 20C for 1 or 2 weeks. At the end of each storage interval, 10 fruit were extracted in hexane and the rest were kept for 7 days at $20 \mathrm{C}$ and evaluated for scald.

Hexane extracts were obtained by dipping apples individually and in sequence in $100 \mathrm{ml}$ of high-performance liquid chromatography-grade hexane for $3 \mathrm{~min}$. UV absorbance of properly diluted hexane extracts was measured from 200 to $290 \mathrm{~nm}$. Extracts displayed five absorption maxima at 200, 232, 258, 269, and 281 $\mathrm{nm}$. Concentrations of $\alpha$ - farnesene in hexane extracts were calculated from $\mathrm{OD}_{232}\left(\mathrm{E}_{232}=27,700\right)$ according to Huelin and Coggiola (1968). Concentrations of all CT species in hexane extracts were assumed to have an extinction coefficient of 25,000 (Anet, 1972) and were calculated from $\mathrm{OD}_{281-290}, \mathrm{OD}_{269-290}$, and $\mathrm{OD}_{258-290}$. These are referred to as CT281, CT269, and CT258, respectively.

Data were subjected to analysis of variance or regression. Means were separated with least significant difference comparisons when applicable. SAS software (SAS Institute, Cary, N.C.) was used for these analyses.

\section{Results}

DPA treatment (Expt. 1). During storage at 0C, concentrations of $\alpha$ - farnesene, CT281, CT269, and CT258 changed significantly over time in 'Cortland' and 'Delicious" apples (Tables 1 and 2). $\alpha-$
Farnesene reached maximum concentrations by 8 weeks and then declined, as commonly observed (e.g., Meigh and Filmer, 1969), and CT increased to a plateau in 12 weeks. However, concentration varied between cultivars and patterns of change over time at $0 \mathrm{C}$ varied between cultivars and DPA treatments (Table 2). In 'Cortland' fruit not treated with DPA, CT281, CT269, and CT258 increased over time, but the CT269 : CT281 and CT258 : CT281 ratios decreased over time, varying between only 0.86 and 2.22 (Table 1). In nontreated 'Delicious' apples, CT269 and CT258 increased faster and to higher concentrations than CT281, producing ratios that varied from 2.42 to 8.61 (Tables 1 and 2).

Applying DPA before storage significantly reduced accumulation of $\alpha-$ farnesene, CT281, CT269, and CT258 in 'Cortland' apples (Tables 1 and 2) but concentrations at each wavelength were not reduced proportionally. DPA significantly increased the CT258 : CT281 ratio but did not alter the CT269 : CT281 ratio (Table 2). The effects of DPA on $\alpha$ - farnesene and at least one CT changed over storage time, while the effects on the two ratios did not (Table 2). For 'Delicious' fruit, however, DPA reduced only $\alpha-$ farnesene and CT281 concentrations late in storage (Tables 1 and 2 ), and this effect was not great enough to alter the CT ratios significantly (Table 2). DPA treatment reduced scald from $23 \%$ to $1 \%$ for 'Cortland' and from $20 \%$ to $5 \%$ for 'Delicious' fruit.

Generally, 'Cortland' fruit contain more $\alpha$ - farnesene and CT281 but less CT258 than 'Delicious' fruit, resulting in much lower CT258 : CT281 or CT269 : CT281 ratios in 'Cortland' than in 'Delicious' fruit (Table 2).

This experiment showed that individual CTs did not change equivalently during storage (Tables 1 and 2). In 'Cortland' apples, CT269 was significantly higher than CT281, while in 'Delicious'

Table 1. Changes in composition of hexane extracts from 'Cortland' and 'Delicious' apples during storage at $0 \mathrm{C}$, with or without DPA treatment before storage. After 16 weeks of storage and 7 days at $20 \mathrm{C}, 23 \%$ and $1 \%$, respectively, of the -DPA and +DPA 'Cortland' apples developed scald but no 'Delicious' apples developed scald. However, 20\% and 5\%, respectively, of the -DPA and +DPA 'Delicious' apples developed scald after 8 additional weeks at $0 \mathrm{C}$.

\begin{tabular}{|c|c|c|c|c|c|c|c|c|c|c|c|c|c|}
\hline \multirow{3}{*}{$\begin{array}{l}\text { Weeks } \\
\text { at } 0 \mathrm{C}\end{array}$} & & \multirow{2}{*}{\multicolumn{2}{|c|}{$\begin{array}{l}\alpha \text {-Farnesene } \\
\left(\mathrm{nmol} \cdot \mathrm{cm}^{-2}\right)\end{array}$}} & \multicolumn{6}{|c|}{$\begin{array}{c}\text { Conjugated triene } \\
\left(\mathrm{nmol} \cdot \mathrm{cm}^{-2}\right)\end{array}$} & \multicolumn{4}{|c|}{ Ratio } \\
\hline & & & & \multicolumn{2}{|c|}{ CT281 } & \multicolumn{2}{|c|}{ CT269 } & \multicolumn{2}{|c|}{ CT258 } & \multicolumn{2}{|c|}{ CT269 : CT281 } & \multicolumn{2}{|c|}{ CT258: CT281 } \\
\hline & & $-\mathrm{DPA}$ & +DPA & -DPA & + DPA & -DPA & $+\mathrm{DPA}$ & -DPA & +DPA & -DPA & +DPA & -DPA & $+\mathrm{DPA}$ \\
\hline \multicolumn{14}{|c|}{ 'Cortland' } \\
\hline 0 & & 37 & 37 & 2.9 & 2.9 & 4.9 & 4.9 & 5.5 & 5.5 & 1.72 & 1.72 & 1.99 & 1.99 \\
\hline 4 & & 107 & 82 & 2.2 & 0.4 & 4.3 & 0.6 & 4.4 & 0.8 & 2.04 & 1.71 & 2.22 & 2.25 \\
\hline 8 & & 121 & 73 & 6.7 & 0.5 & 9.8 & 1.2 & 7.4 & 1.0 & 1.47 & 3.42 & 1.12 & 2.25 \\
\hline 12 & & 90 & 63 & 10.3 & 2.1 & 14.1 & 3.9 & 9.6 & 3.6 & 1.39 & 1.84 & 0.96 & 1.64 \\
\hline 16 & & 95 & 67 & 11.8 & 2.7 & 15.0 & 4.2 & 9.9 & 3.8 & 1.28 & 1.54 & 0.86 & 1.42 \\
\hline Significance & & & & & & & & & & & & & \\
\hline Linear & & $* *$ & NS & $* * *$ & NS & $* * *$ & NS & $* * *$ & NS & $* * *$ & NS & $* * *$ & NS \\
\hline Quadratic & & $* * *$ & $* * *$ & $* * *$ & $* * *$ & $* * *$ & $* * *$ & $* * *$ & $* * *$ & $* * *$ & NS & $* * *$ & NS \\
\hline Cubic & & $* * *$ & $* * *$ & $* * *$ & $* * * *$ & $* * *$ & $* * *$ & $* * *$ & $* * *$ & $* * *$ & NS & $* * *$ & NS \\
\hline \multicolumn{14}{|c|}{ 'Delicious' } \\
\hline 0 & & 3 & 3 & 0.2 & 0.2 & 1.2 & 1.2 & 1.5 & 1.5 & 6.80 & 6.80 & 8.61 & 8.61 \\
\hline 4 & & 74 & 60 & 0.8 & 1.0 & 4.5 & 3.6 & 5.9 & 3.7 & 5.39 & 3.66 & 3.83 & 3.68 \\
\hline 8 & & 86 & 68 & 3.5 & 3.1 & 9.4 & 8.3 & 9.8 & 8.0 & 2.69 & 2.64 & 2.83 & 2.54 \\
\hline 12 & - & 68 & 59 & 4.6 & 3.7 & 11.3 & 11.2 & 11.3 & 12.2 & 2.49 & 3.01 & 2.50 & 3.26 \\
\hline 16 & & 43 & 35 & 5.0 & 3.1 & 12.4 & 11.2 & 12.1 & 12.1 & 2.49 & 3.64 & 2.42 & 3.92 \\
\hline \multicolumn{14}{|l|}{ Significance } \\
\hline Linear & & NS & * & $* * *$ & $* * *$ & $* * *$ & $* * *$ & $* * *$ & $* * *$ & $* * *$ & $* *$ & $* * *$ & $* *$ \\
\hline Quadratic & & $* * *$ & $* * *$ & $* * *$ & $* * *$ & $* * *$ & $* * *$ & $* * *$ & $* * *$ & $* * *$ & $* * *$ & $* * *$ & $* * *$ \\
\hline Cubic & & $* * *$ & $* * *$ & $* * *$ & $* * *$ & $* * *$ & $* * *$ & $* * *$ & $* * *$ & $* * *$ & $* * *$ & $* * *$ & $* * *$ \\
\hline
\end{tabular}

${ }^{\mathrm{z}}$ Data are means of six replications.

${ }_{\mathrm{Ns}, *, * * * * *}$ Nonsignificant or significant at $P \leq 0.05,0.01$, or 0.001 , respectively. 
apples, CT269 and CT258 were significantly higher than CT281 but similar to each other. When data for the two cultivars were combined, CT269 and CT258 were similar and both were higher than CT281. The differences in CT values, depending on which absorption maximum is used for measurement, are demonstrated in the varying CT258 : CT281 and CT269 : CT281 ratios during storage.

Harvest time (Expt. 2). As time at 0C increased from 16 to 30 weeks, $\alpha$ - farnesene, CT281, CT269, CT258, and the CT258 : CT281 ratio declined greatly in early-harvested 'Cortland' apples, but the CT269 : CT281 ratio remained unchanged (Table 3). However, despite marked reductions of all of the components in fruit peel during this period, the percentage of fruit that developed scald after storage increased from $23 \%$ to $60 \%$.
When stored for 30 weeks at 0C, the late-harvested fruit contained higher concentrations of $\alpha$-farnesene, CT281, CT269, and CT258 than early-harvested fruit (Table 3). Differences in CTs measured at the three absorption maxima were not proportional, however, because the CT258 : CT281 ratio was higher in lateharvested than in early-harvested fruit. Despite having higher concentrations of $\alpha$ - farnesene and CTs, late-harvested fruit developed much less scald than the early-harvested fruit (21\% vs. $60 \%)$ (Table 3).

When the late-harvested fruit were kept for an additional 15 weeks at 0C, $\alpha$ - farnesene concentration declined and CT269 and CT258 rose, while CT281 remained unchanged (Table 3). These CT changes produced higher CT258: CT281 and CT269 : CT281 ratios after 45 weeks of storage. However, scald susceptibility did

Table 2. Statistical analyses of changes in $\alpha$-farnesene and conjugated trienes in apple peel during storage at $O C$, as affected by storage time, DPA treatment, and cultivar.

\begin{tabular}{|c|c|c|c|c|c|c|}
\hline \multirow[b]{2}{*}{ Variable } & \multirow{2}{*}{$\begin{array}{l}\alpha \text {-Farnesene } \\
\left(\mathrm{nmol} \cdot \mathrm{cm}^{-2}\right)\end{array}$} & \multicolumn{3}{|c|}{$\begin{array}{l}\text { Conjugated triene } \\
\left(\mathrm{nmol} \cdot \mathrm{cm}^{-2}\right)\end{array}$} & \multicolumn{2}{|c|}{ Ratio } \\
\hline & & CT281 & CT269 & $\mathrm{CT} 258$ & CT269: CT281 & CT258: CT281 \\
\hline \multicolumn{7}{|c|}{ Cortland } \\
\hline Storage (S) & $* * *$ & $* * *$ & $* * *$ & $* * *$ & NS & * \\
\hline DPA & $* * *$ & $* * *$ & $* * *$ & $* * *$ & NS & * \\
\hline$S \times D P A$ & $* * *$ & $* * *$ & $* * *$ & $* * *$ & NS & NS \\
\hline \multicolumn{7}{|c|}{ Delicious } \\
\hline S & $* * *$ & $* * *$ & $* * *$ & $* * * *$ & $* * *$ & $* * *$ \\
\hline DPA & $* * *$ & $* * *$ & NS & NS & NS & NS \\
\hline $\mathrm{S} \times \mathrm{DPA}$ & $*$ & $* * *$ & NS & NS & NS & NS \\
\hline \multicolumn{7}{|c|}{ Comparison of cultivars } \\
\hline Cortland (C) & 77 & 4.26 & 6.30 & 5.17 & 1.84 & 1.67 \\
\hline Delicious (D) & 50 & 2.51 & 7.54 & 7.97 & 3.96 & 4.52 \\
\hline Significance & $* * *$ & $* * *$ & NS & $* * *$ & $* * *$ & $* * *$ \\
\hline \multicolumn{7}{|c|}{ Comparison of conjugated trienes ${ }^{7}$} \\
\hline $\mathrm{C}$ & & $4.26 \mathrm{~b}$ & $6.30 \mathrm{a}$ & $5.17 \mathrm{ab}$ & & \\
\hline $\mathrm{D}$ & & $2.51 \mathrm{~b}$ & $7.51 \mathrm{a}$ & $7.78 \mathrm{a}$ & & \\
\hline $\mathrm{C}+\mathrm{D}$ & & $3.39 \mathrm{~b}$ & $6.91 \mathrm{a}$ & $6.47 \mathrm{a}$ & & \\
\hline
\end{tabular}

${ }^{2}$ Means within a row not followed by a common letter are significantly different at $P \leq 0.05$, by Duncan's multiple range test.

Ns, ${ }^{* * *}, * * *$ Nonsignificant or significant at $P \leq 0.05,0.01$, or 0.001 , respectively.

Table 3. Comparisons of hexane-extractable components from early-harvested (26 Sept., with 16 or 30 weeks of storage at $0 \mathrm{C}$ ) and late-harvested ( 10 Oct., with 30 or 45 weeks of storage at $0 \mathrm{C}$ ) 'Cortland' apples on removal from cold storage. Data are means of three replications. Scald was evaluated after 7 days at $20 \mathrm{C}$.

\begin{tabular}{|c|c|c|c|c|c|c|c|c|}
\hline \multirow{2}{*}{$\begin{array}{l}\text { Harvest } \\
\text { date }\end{array}$} & \multirow{2}{*}{$\begin{array}{l}\text { Weeks } \\
\text { at } 0 \mathrm{C}\end{array}$} & \multirow{2}{*}{$\begin{array}{l}\alpha \text {-Farnesene } \\
\left(\mathrm{nmol} \cdot \mathrm{cm}^{-2}\right)\end{array}$} & \multicolumn{3}{|c|}{$\begin{array}{l}\text { Conjugated triene } \\
\left(\mathrm{nmol} \cdot \mathrm{cm}^{-2}\right)\end{array}$} & \multicolumn{2}{|c|}{ Ratio } & \multirow{2}{*}{$\begin{array}{l}\text { Scald } \\
(\%)\end{array}$} \\
\hline & & & CT281 & CT269 & CT258 & CT269: CT281 & CT258: CT281 & \\
\hline \multicolumn{9}{|c|}{ Early-harvested fruit, increasing storage time } \\
\hline \multirow[t]{2}{*}{26 Sept. } & 16 & 95 & 11.8 & 15.0 & 9.9 & 1.28 & 0.86 & 23 \\
\hline & 30 & 9 & 2.9 & 3.4 & 1.4 & 1.20 & 0.53 & 60 \\
\hline Significance & $* * *$ & $* * *$ & $* * *$ & $* * *$ & NS & $*$ & $* *$ & $* *$ \\
\hline \multicolumn{9}{|c|}{ Early-vs. late-harvested fruit } \\
\hline 26 Sept.-. & 30 & 9 & 2.9 & 3.4 & 1.4 & 1.20 & 0.53 & 60 \\
\hline 10 Oct. & 30 & 36 & 5.8 & 9.1 & 7.2 & 1.58 & 1.27 & 21 \\
\hline Significance & $* * *$ & $* * *$ & $* * *$ & $* * *$ & $* * *$ & NS & $* * *$ & $* *$ \\
\hline \multicolumn{9}{|c|}{ Late-harvested fruit, increasing storage time } \\
\hline \multirow[t]{2}{*}{10 Oct. } & 30 & 36 & 5.8 & 9.1 & 7.2 & 1.58 & 1.27 & 21 \\
\hline & 45 & 22 & 5.7 & 15.5 & 15.2 & 2.73 & 2.67 & 24 \\
\hline Significance & & $* *$ & NS & $* * *$ & $* * *$ & ** & $* * *$ & NS \\
\hline
\end{tabular}



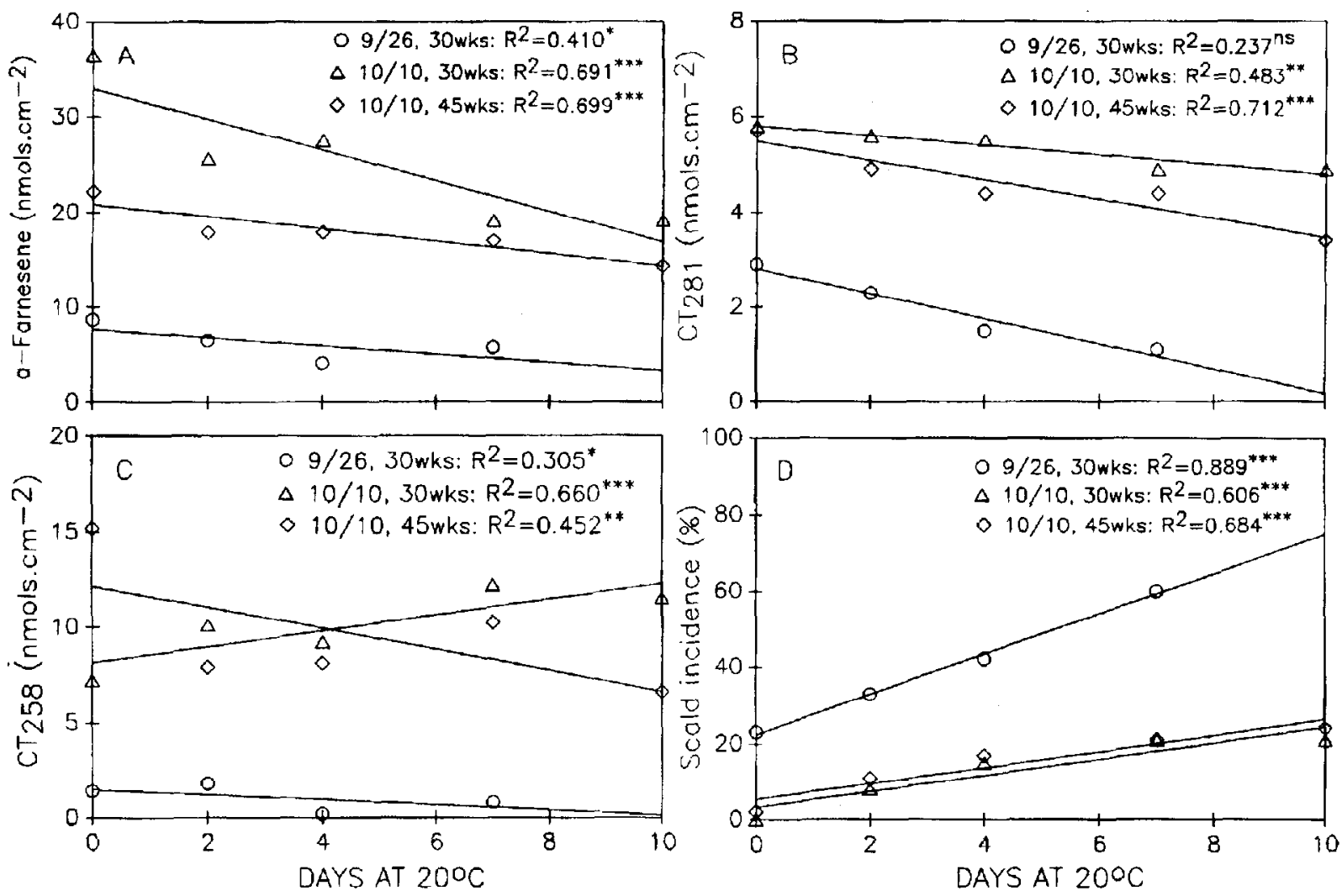

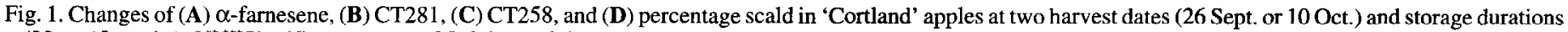
(30 or 45 weeks). ${ }^{* * * * * *}$ Significant at $P \leq 0.05,0.01$, or 0.001 .

not change with extended storage time for these late-harvested, scald-resistant fruit.

Scald usually develops after fruit are transferred from cold storage to higher temperatures. At 20C, linear increases in percentage scald occurred over time, but they usually were accompanied by linear decreases in $\alpha$ - farnesene and CT281 in apple peel. However, CT258 did not change consistently (Fig. 1). Typical UV absorption spectra of hexane extracts from scald-susceptible and scald-resistant 'Cortland' apples during this time showed that, in the early-picked, scald-susceptible fruit (Fig. 2A), all CTs (at 258, 269 , and $281 \mathrm{~nm}$ ) decreased about equivalently during 7 days at 20C. However, in late-picked, scald-resistant fruit (Fig. 2B), CTs were much higher when fruit were removed from storage, and CT281 did not decline significantly during 10 days at 20C, while CT258 and CT269 increased significantly $(P \leq 0.01)$. These differences were illustrated by the CT258 : CT281 ratios, which remained $<1.0$ in the early-harvested fruit but rose from $\approx 1.4$ to $\approx 2.4$ during 10 days at $20 \mathrm{C}$ in the late-harvested fruit (data not shown). Differences were less pronounced when CT269 : CT281 ratios were compared for the two lots of fruit (data not shown).

When random samples of fruit were taken for the measurements shown in Fig. 2, fruit with different amounts of scald were included. To obtain an indication of differences among fruit with different amounts of scald after 7 days at 20C, single (nonreplicated) 10-fruit samples with specific scald intensities were selected from among the replications and extracted. Those with the most scald seemed to contain the most $\alpha$ - farnesene, but there was little difference among them in CT281, CT269, or CT258, except when harvest dates were compared (Table 4). In the early-harvested fruit, the CT258 : CT281 ratios were close to unity; but, in the late-harvested, less scald-susceptible fruit, they were close to 2.0.

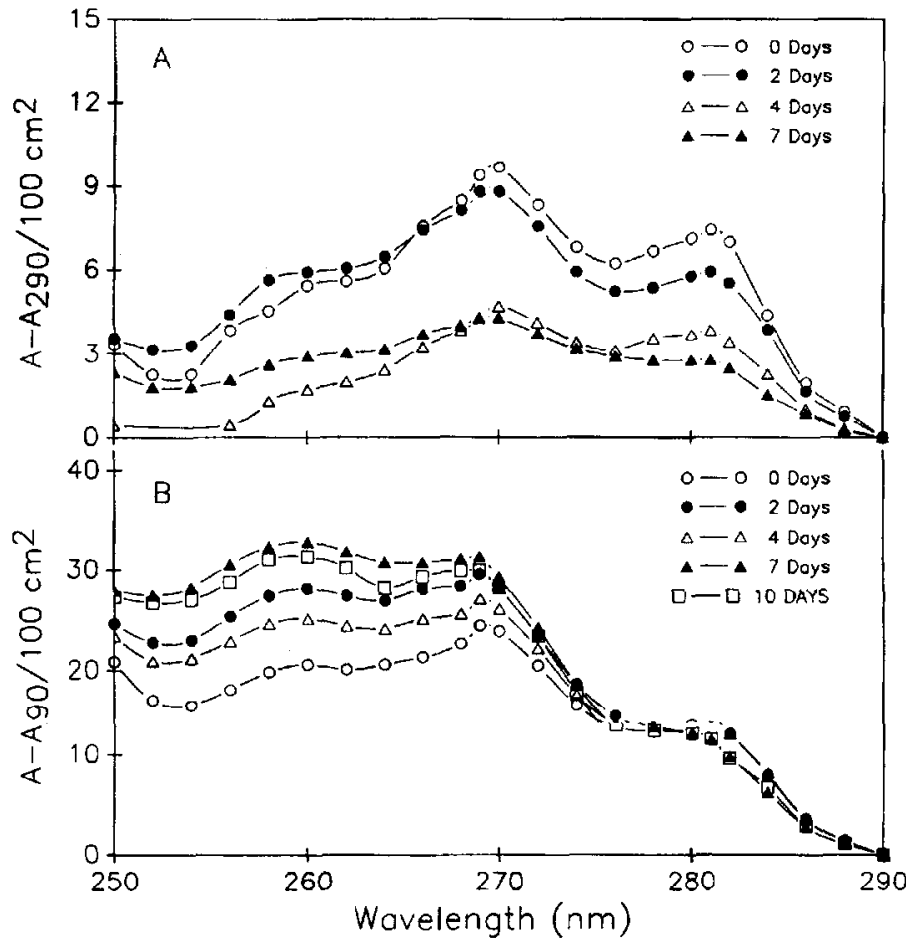

Fig. 2. Typical ultraviolet absorbance spectra of hexane extracts from (A) earlyharvested and (B) late-harvested 'Cortland' apples at $20 \mathrm{C}$ after 30 weeks of storage at $0 \mathrm{C}$.

Storage temperature (Expt. 3). To test the effects of temperature on scald induction, 'Cortland' apples were kept at 20C for 1 or 2 weeks or at $0 \mathrm{C}$ for 12 or 24 weeks. More $\alpha$ - farnesene 
accumulated at 20C than at 0C (Table 5). In contrast, more CT281 accumulated at 0C than at 20C. CT269 values had become slightly higher at 0C than at 20C, but CT258 values were slightly lower in fruit at 0C than in those at 20C. CT258 : CT281 and CT269: CT281 ratios declined over time at $20 \mathrm{C}$, but these ratios still seemed to remain higher at $20 \mathrm{C}$ than at $0 \mathrm{C}$. Fruit stored at $0 \mathrm{C}$ developed scald after transfer to 20C. About $2 \%$ of fruit kept continuously at $20 \mathrm{C}$ exhibited slight scald-like symptoms, but these symptoms were present at harvest and their origin is unknown.

\section{Discussion}

Since evidence was first presented that CTs (later defined as CT281) arc oxidation products of $\alpha$ - farnesene (Anet, 1969; Huelin and Coggiola, 1970a) and correlated with scald development (Anet and Coggiola, 1974; Huelin and Coggiola, 1970b), this concept has dominated scald research, and no alternative hypothesis of scald development has been advanced, even though data sometimes have been hard to rationalize with this scheme.

Of the data reported here, most are not consistent with this concept.

1) After long periods of storage, later-harvested 'Cortland' apples contained twice the CT281 concentrations as early-harvested fruit, yet the later-harvested fruit developed only one-third as much scald and its intensity was less (Tables 3 and 4).

2) The 'Cortland' apples harvested 26 Sept. had one-fourth as much CT281 (2.9 vs. $11.8 \mathrm{nmol} \cdot \mathrm{cm}^{-2}$ ) but developed three times more scald (60\% vs. $23 \%$ ) after 30 than after 16 weeks of storage at 0C (Table 3).

3) Apples with greatly varying intensities of scald development in the same harvest contained almost equal concentrations of CT281 (Table 4).

4) Apples stored continuously at 20C developed substantial concentrations of CT281 but did not develop scald (Table 5).

These inconsistencies may result, at least in part, from using CT281 values to represent the total CT concentrations in fruitsurface extracts. Anet (1969) showed that at least two hexane-soluble CT compounds formed in vitro. $\alpha$ - Farnesene oxidation in vivo may produce a complex mixture of CT compounds, the composition of which may vary greatly with oxidative conditions. Huelin and Coggiola (1970a) mentioned that hexane extracts from scald-resistant apples often displayed a high peak at $258 \mathrm{~nm}$, but they did not expand on this observation. We found that changes over time in the absorption spectra of fruit extracts varied among absorption maxima (Fig. 2). When overall values for CT281, CT269, and CT258 were compared, CT269 was different from CT281 in 'Cortland' and 'Delicious', CT258 was different from CT281 in 'Delicious', and, in the combination of 'Cortland' and 'Delicious', CT269 and CT258 were not different from each other (Table 2). The absorption maximum of the hexane extract may represent the maxima of certain $\mathrm{CT}$ species that dominate in this mixture, or it may represent common absorption characteristics of

Table 4. Changes in components of hexane extracts of 'Cortland' apples with a range of scald intensities after 7 days at $20 \mathrm{C}$ following storage for 30 weeks at $0 \mathrm{C}$. Single unreplicated samples of 10 apples with the same scald intensity were selected for hexane extraction from among the harvest-date replicates.

\begin{tabular}{|c|c|c|c|c|c|c|}
\hline \multirow{2}{*}{$\begin{array}{l}\text { Scald } \\
\text { score }^{z}\end{array}$} & \multirow{2}{*}{$\begin{array}{l}\alpha \text {-Farnesene } \\
\left(\mathrm{nmol} \cdot \mathrm{cm}^{-2}\right)\end{array}$} & \multicolumn{3}{|c|}{$\begin{array}{l}\text { Conjugated triene } \\
\left(\mathrm{nmol} \cdot \mathrm{cm}^{-2}\right)\end{array}$} & \multicolumn{2}{|c|}{ Ratio } \\
\hline & & CT281 & CT269 & CT258 & CT269: CT281 & CT258: CT281 \\
\hline \multicolumn{7}{|c|}{ Harvested 26 Sept. } \\
\hline 0 & 5.7 & 1.2 & 2.0 & 1.1 & 1.7 & 0.9 \\
\hline 1 & 7.0 & 1.5 & 2.5 & 1.7 & 1.7 & 1.1 \\
\hline 2 & 3.4 & 1.3 & 2.3 & 1.4 & 1.8 & 1.1 \\
\hline 3 & 5.9 & 1.2 & 1.3 & 0.4 & 1.1 & 0.3 \\
\hline 4 & 9.5 & 1.5 & 1.5 & 0.7 & 1.0 & 0.5 \\
\hline 5 & 9.8 & 1.5 & 1.5 & 0.9 & 1.0 & 0.6 \\
\hline \multicolumn{7}{|c|}{ Harvested 10 Oct. } \\
\hline 0 & 17.3 & 4.7 & 11.0 & 10.3 & 2.3 & 2.2 \\
\hline 1 & 22.0 & 5.1 & 13.5 & 13.6 & 2.7 & 2.6 \\
\hline 2 & 40.4 & 6.4 & 12.7 & 12.9 & 2.0 & 2.0 \\
\hline
\end{tabular}

Scald score: $0=$ no scald, $1=1 \%$ to $10 \%, 2=11 \%$ to $33 \%, 3=34 \%$ to $66 \%, 4=\overline{67 \%}$ to $100 \%, 5=$ apples with $>67 \%$ of surface affected at removal from storage.

Table 5. Changes in 'Cortland' apples during storage at 0 or $20 \mathrm{C}$ after harvest on 5 Oct. 1990. Scald on stored fruit was determined after an additional 7 days at $20 \mathrm{C}$. Data are means of six replications.

\begin{tabular}{|c|c|c|c|c|c|c|c|c|}
\hline \multirow{2}{*}{$\begin{array}{l}\text { Storage } \\
\text { time } \\
\text { (weeks) }\end{array}$} & \multirow{2}{*}{$\begin{array}{c}\text { Storage } \\
\text { temp } \\
\left({ }^{\circ} \mathrm{C}\right)\end{array}$} & \multirow{2}{*}{$\begin{array}{l}\alpha \text {-Farnesene } \\
\left(\mathrm{nmol} \cdot \mathrm{cm}^{-2}\right)\end{array}$} & \multicolumn{3}{|c|}{$\begin{array}{l}\text { Conjugated triene } \\
\left(\mathrm{nmol} \cdot \mathrm{cm}^{-2}\right)\end{array}$} & \multicolumn{2}{|c|}{ Ratio } & \multirow{2}{*}{$\begin{array}{r}\text { Scald } \\
(\%)\end{array}$} \\
\hline & & & CT281 & CT269 & CT258 & CT269: CT281 & CT258: CT281 & \\
\hline \multicolumn{9}{|c|}{ Early-harvested fruit, increasing storage time } \\
\hline 0 & --- & 17 & 1.3 & 4.5 & 5.2 & 4.3 & 5.1 & --- \\
\hline 1 & 20 & 134 & 3.4 & 9.9 & 11.5 & 3.0 & 3.5 & --- \\
\hline 2 & 20 & 112 & 4.4 & 10.5 & 10.5 & 2.4 & 2.4 & 2 \\
\hline 12 & 0 & 93 & 8.1 & 12.1 & 9.8 & 1.5 & 1.2 & --- \\
\hline 24 & 0 & 47 & 6.3 & 13.1 & 7.9 & 1.7 & 1.3 & 34 \\
\hline $\mathrm{LSD}_{0.05}$ & & 16 & 1.6 & 2.2 & 1.7 & 1.4 & 1.9 & 18 \\
\hline
\end{tabular}


most or all of these species. However, even in the latter case, the specific absorption characteristics of different species may vary. In the experiments reported here, the CT258 : CT281 and CT269 : CT281 ratios varied greatly with experimental conditions, and we interpret these differences to indicate the relative abundances of different CT species or groups of species under different conditions. Viewed in this way, the data offer a new perspective on scald development.

In these experiments, a negative relationship repeatedly occurred between the CT258 : CT281 ratio and scald development under varying conditions, as follows.

1) In 'Cortland' and 'Delicious' apples, the CT258: CT281 ratios of fruit not treated with DPA dropped with time during storage at $0 \mathrm{C}$ (Tables 1 and 3), while scald incidence increased with storage time (Table 3 ).

2) After 16 weeks at 0C, among 'Cortland' apples with a CT258 : CT281 ratio of $0.9,23 \%$ developed scald, while 'Delicious' apples with a CT258 : CT281 ratio of 2.4 developed no scald unless they were stored for an additional 8 weeks, after which $20 \%$ developed scald (Table 1).

3) Later-harvested, scald-resistant 'Cortland' apples had higher CT258 : CT281 ratios than early-harvested, more scald-susceptible fruit (Tables 3 and 4).

4) 'Cortland' apples kept continuously at 20C had high CT258 : CT281 ratios and did not scald, while those at 0C had low CT258 : CT281 ratios and scalded after transfer to 20C (Table 5).

Thus, the CT258 values and CT258 : CT281 ratios seemed to be better indicators of scald development than the CT281 values. In these experiments, a CT258 : CT281 ratio of about 22.0 was associated with little or no scald development in each of the postharvest conditions tested, while ratios of about 11.0 were associated with significant scald development. The CT269 : CT281 ratios generally reflected the CT258 : CT281 ratios, but differences usually were less distinct when comparing lots of fruit with different scald potentials.

Scald development consists of induction and symptom-expression periods (Bramlage and Meir, 1990). Induction apparently occurs only at low temperatures, while symptoms develop at either low or high temperatures, most commonly the latter (Fig. 1D). The role of CTs in this process has not been defined, but they could be involved in the peroxidation of membrane lipids, an action that ultimately disrupts cellular organization, and, thus, be agents of symptom expression after slow cell disruption.

If CT281 is involved directly in scald development, its concentrations likely would be highest when symptoms develop. However, like $\alpha$ - farnesene, CT281 reached a maximum and then declined during prolonged storage of 'Cortland' apples (Table 3), a result that is similar to the CT281 changes in early-picked apples reported by Anet (1972). Yet, 23\% of the fruit scalded after 16 weeks and $60 \%$ scalded after 30 weeks. Similarly, during symptom development after transfer to $20 \mathrm{C}$, percentage scald increased linearly during 10 days, while CT281 concentrations declined linearly (Fig. 1).

Since CT formation is autocatalyzed, declining concentrations should indicate increasing rates of metabolism-catabolism of these free-radical species, and, since declines accompanied scald development (Fig. 1), CT metabolites-catabolites may be involved more in symptom development than CT281. Since conditions of low and high scald development produced high and low CT258 : CT281 ratios, respectively, regardless of CT281 concentrations, this ratio may reflect CT281 metabolism-catabolism to CT258 in apple peel.

We propose that, if CTs are associated with scald development, the metabolites-catabolites of CT281 are involved more directly in cellular disruption than CT281. We interpret our results to suggest that CT281 is metabolized to CT258 and some unknown compound in one of two ways, as follows:

\section{A) $\alpha$-farnesene $\rightarrow$ CT281 $\rightarrow$ CT258 $\rightarrow ? \rightarrow$ scald or \\ B) $\alpha$-farnesene $\rightarrow$ CT281 $\rightarrow$ CT258 $\rightarrow$ ? \\ $\rightarrow \mathrm{CT} 281 \rightarrow ? \rightarrow$ scald}

In either sequence, we envision two critical control points: $\alpha-$ farnesene $\rightarrow$ CT281 and either CT258 $\rightarrow$ ? or CT281 $\rightarrow$ ? DPA apparently suppressed the first of these and may or may not have suppressed the second.

In sequence $\mathrm{A}$, if the second control point is impeded, a high CT258 : CT281 ratio should be produced and little scald should develop, regardless of CT281 concentration. In sequence B, impeding the second control point diverts CT281 to CT258, which is inactive in scald development. Therefore, the toxic metabolite of CT281 is avoided, and again a high CT258 : CT281 ratio should occur and little scald develop, regardless of CT281 concentration. In either sequence, if the second control point is "open," then scald development is only a function of the peroxidation of $\alpha$ - farnesene to CT281.

Other interpretations of these results are possible, but we believe that they are less likely to represent the conditions of scald development. For example, the sequence could be $\alpha-$ farnesene $\rightarrow$ CT258 $\rightarrow$ CT281, or it could be that $\alpha$ - farnesene may be oxidized directly to either CT258 or CT281. However, neither of these sequences addresses three important points. First, CT281 is not the direct determinant in scald development. Second, CT258 and CT281 had opposite associations with scald. Third, CT258 : CT281 ratios had greater associations with scald than CT281 or CT258 alone. (We have extensive unpublished data supporting the second and the third points.) If CT258 is metabolized to CT281, then scald development should be a function of CT281 formation, which it was not (Tables 3 and 4), and CT258, as a precursor of CT281, should not be inversely related to scald development, which it was (Tables 3-5). In the second of these sequences, scald should be a function of CT281 concentrations, assuming that it can be metabolized freely to its toxic product. This second alternative sequence explains why $\alpha$ - farnesene is not a direct determinant of scald, but does not explain why CT281 is not the direct determinant. Nevertheless, considerably more research is needed to clarify the pathway for $\alpha$ - farnesene oxidation in apple peel.

CT258 and CT281 probably represent groups of compounds rather than individual species, with CT269 being influenced by both groups. Thus, the proposed sequence may represent metabolic fluxes being directed by various redox conditions existing in the cells. While this proposal is tentative, we believe that it represents possible $\mathrm{CT}$ relationships to scald development better than a simple peroxidation of $\alpha$ - farnesene to CT281, since a highly complex family of compounds probably exists in this system.

\section{Literature Cited}

Anet, E.F.L.J. 1969. Autoxidation of $\alpha-$ farnesene. Austral. J. Chem. 22:2403-2410.

Anet, E.F.L.J. 1972. Superficial scald, a functional disorder of stored apples. IX. Effects of maturity and ventilation. J. Sci. Food Agr. 23:763-769.

Anet, E.F.L.J. 1974. Superficial scald, a functional disorder of stored apples. XI. Apple antioxidants. J. Sci. Food Agr. 25:299-304.

Anet, E.F.L.J. and I.M. Coggiola. 1974. Superficial scald, a functional disorder of stored apples. X. Control of $\alpha-$ farnesene autoxidation. J. Sci. Food Agr. 25:293-298.

Bramlage, W.J. and S. Meir. 1990. Chilling injury of crops of temperate origin, p. 3749. In: C.Y. Wang (ed.). Chilling injury of horticultural 
crops. CRC Press, Boca Raton, Fla.

Huelin, F.E. and I.M. Coggiola. 1968. Superficial scald, a functional disorder of stored apples. IV. Effect of variety, maturity, oiled wraps, and diphenylamine on concentration of $\alpha$ - farnesene in the fruit. J. Sci. Food Agr. 19:297-301.

Huelin, F.E. and I.M. Coggiola. 1970a. Superficial scald, a functional disorder of stored apples. V. Oxidation of $\alpha$ - farnesene and its inhibition by diphenylamine. J. Sci. Food Agr. 21:44-48.

Huelin, F.E. and I.M. Coggiola. 1970b. Superficial scald, a functional disorder of stored apples. VII. Effects of applied farnesene, temperature, and diphenylamine on scald and the concentration and oxidation of $\alpha-$ farnesene in the fruit. J. Sci. Food Agr. 21:584-589.

Huelin, F.E. and K.E. Murray. 1966. $\alpha-$ Farnesene in the natural coating of apples. Nature (London) 210:1260-1261.

Ingle, M. and M.C. D'Souza. 1989. Physiology and control of superficial scald of apples: A review. HortScience 24:28-31.

Meigh, D.F. 1970. Apple scald, p. 555-569. In: A.C. Hulme (ed.). The biochemistry of fruits and their products. Academic Press, London.

Meigh, D.F. and A.A.E. Filmer. 1969. Natural skin coating of the apple and its influence on scald in storage. III. $\alpha-$ Farnesene. J. Sci. Food Agr. 20:139-143.

Meir, S. and W.J. Bramlage. 1988. Antioxidant activity in 'Cortland' apple peel and susceptibility to superficial scald after storage. J. Amer. Soc. Hort. Sci. 113:418-422.

Murray, K.E., F.E. Huelin, and J.B. Davenport. 1964. Occurrence of $\alpha-$ farnesene in the natural coating of apples. Nature (London) 204:80. 